\title{
Date of First Ever Onset of Heart Failure
}

National Cancer Institute

\section{Source}

National Cancer Institute. Date of First Ever Onset of Heart Failure. NCI Thesaurus. Code C91340.

The date of the beginning of the first ever occurrence of heart failure. 